\title{
Comparison of Biomechanical Properties of Dura Mater Substitutes and Cranial Human Dura Mater : An In Vitro Study
}

\author{
Ceren Kizmazoglu, ${ }^{1}$ Hasan Emre Aydin, ${ }^{2}$ Ismail Kaya, ${ }^{2}$ Murat Atar, ${ }^{3}$ Bugra Husemoglu, ${ }^{4}$ Orhan Kalemci, ${ }^{1}$ Gulden Sozer, ${ }^{5}$ \\ Hasan Havitcioglu ${ }^{4,6}$ \\ Department of Neurosurgery, Dokuz Eylul University School of Medicine, Izmir, Turkey \\ Department of Neurosurgery, ${ }^{2}$ Kutahya Health Science University Evliya Celebi Training and Research Hospital, Kutahya, Turkey \\ Department of Neurosurgery, ${ }^{3}$ Sultan Abdulhamid Han Training and Research Hospital, Istanbul, Turkey \\ Department of Biomechanics, ${ }^{4}$ Dokuz Eylul University School of Medicine Health Science Institute, Izmir, Turkey \\ Department of Pathology, Forensic Medicine Institution, Izmir, Turkey \\ Department of Orthopedics and Traumatology, ${ }^{6}$ Dokuz Eylul University School of Medicine, Izmir, Turkey
}

Objective : The aim of this study was to investigate the biomechanical differences between human dura mater and dura mater substitutes to optimize biomimetic materials.

Methods : Four groups were investigated. Group I used cranial dura mater $(n=10)$, group II used Gore-Tex ${ }^{\circledR}$ Expanded Cardiovascular Patch (W.L. Gore \& Associates Inc., Flagstaff, AZ, USA) (n=6), group III used Durepair (Medtronic Inc., Goleta, CA, USA) $(n=6)$, and group IV used Tutopatch ${ }^{\oplus}$ (Tutogen Medical $\mathrm{GmbH}$, Neunkirchen am Brand, Germany) ( $\left.n=6\right)$. We used an axial compression machine to measure maximum tensile strength.

Results : The mean tensile strengths were $7.01 \pm 0.77 \mathrm{MPa}$ for group I, $22.03 \pm 0.60 \mathrm{MPa}$ for group II, $19.59 \pm 0.65 \mathrm{MPa}$ for group III, and $3.51 \pm 0.63 \mathrm{MPa}$ for group IV. The materials in groups II and III were stronger than those in group I. However, the materials in group IV were weaker than those in group $\mathrm{I}$.

Conclusion : An important dura mater graft property is biomechanical similarity to cranial human dura mater. This biomechanical study contributed to the future development of artificial dura mater substitutes with biomechanical properties similar to those of human dura mater.

Key Words : Mechanics · Collagen · Dura mater · Pericardium · Polytetrafluoroethylene.

\section{INTRODUCTION}

Duraplasty has been used for dural defect repair for many years in neurosurgical operations. Dural defects can be caused by many reasons, such as congenital defects, trauma, iatrogenic injuries, inflammatory or tumour invasion. Synthetic dura mater and collagen biomatrix are used to prevent dural fistulae ${ }^{11}$. Human dura consists of mainly collagen and elastin

- Received : May 22, 2019 •Revised : July 11, 2019 •Accepted : July 26, 2019

- Address for reprints : Ceren Kizmazoglu

Department of Neurosurgery, Dokuz Eylul University School of Medicine, 35340 Balcova, Izmir 35000, Turkey

Tel : +90-232-412-33-01, Fax : +90-232-412-97-97, E-mail : ceren.kizmazoglu@gmail.com, ORCID : https://orcid.org/0000-0001-6146-0842

This is an Open Access article distributed under the terms of the Creative Commons Attribution Non-Commercial License (http://creativecommons.org/licenses/by-nc/4.0) which permits unrestricted non-commercial use, distribution, and reproduction in any medium, provided the original work is properly cited. 
fibres $^{16,18)}$. Human dura mater is also described as a viscoelastic material ${ }^{8)}$.

Ideal dura mater material properties include non-neurotoxic, non-immunogenic, non-inflammatory, non-viral/ prion, concordant with the connective tissue, non-adhesive to other tissues, watertight, viscoelastic and biomechanically resistant ${ }^{11)}$.

Viscoelasticity is defined as a property of materials that exhibit both viscous and elastic characteristics when undergoing deformation ${ }^{24)}$. Viscoelastic materials are excellent impact absorbers.

During artificial dura mater production, it is important that the substitute has properties that are biologically and biomechanically similar to human dura. However, no studies were found on biomechanical comparisons of these dura mater substitutes and human dura in the literature.

The aim of this study was to compare the biomechanical properties of dura mater substitutes with human dura mater and contribute to the future development of these materials.

\section{MATERIALS AND METHODS}

All of the experimental procedures used in the present study were approved by the Ethics Committee of the affiliated institution. This study was conducted at Dokuz Eylul University School of Medicine Health Science Institute Biomechanics Laboratory (reference number : 2017-14/5).

Artificial dura mater has been produced to substitute human dura mater. Gore-Tex ${ }^{\circledR}$ Expanded Cardiovascular Patch
(W.L. Gore \& Associates Inc., Flagstaff, AZ, USA), which is produced from polytetrafluoroethylene (PTFE), is synthetic and hydrophobic ${ }^{1,10)}$. Durepair ${ }^{\circledR}$ (Medtronic Inc., Goleta, CA, USA), which is produced from bovine skin collagen, is xenogeneic and should not be used in patients with a collagen allergy ${ }^{28)}$. Tutopatch ${ }^{\circledR}$ (Tutogen Medical GmbH, Neunkirchen am Brand, Germany), which is produced from bovine pericardium, is xenogeneic and exposed to the Tutoplast process ${ }^{11}$. The Tutoplast process is chemical sterilization, which increases the strength of bovine pericardium to enzymatic breakdown and decreases its antigenicity.

Fresh cranial human dura mater specimens were collected from forensic medicine. Four groups were included. Group 1 used cranial dura mater $(\mathrm{n}=10)$, group 2 used Gore-Tex ${ }^{\circledR} \mathrm{Ex}-$ panded Cardiovascular Patch (W.L. Gore \& Associates Inc.) $(n=6)$, group 3 used Durepair ${ }^{\circledR}$ (Medtronic Inc.) $(n=6)$, and group 4 used Tutopatch ${ }^{\circledR}$ (Tutogen Medical GmbH) $(\mathrm{n}=6)$.

\section{Sample preparation}

The specimens were taken at autopsy from the right frontal region of 10 cranial human dura mater (four male and six female) with a mean age of $42.57 \pm 8.71$ (range, $31-54$ years). Human dura mater specimens were fresh and not fixed with formalin. To prevent mechanical damage, human dura mater samples were excised widely. The samples were frozen at $-4^{\circ} \mathrm{C}$ for 24-120 hours before testing. Human specimens were thawed at room temperature for 6 hours before mechanical testing.

A custom designed die was used to cut the samples from human dura mater and other dura substitutes. All samples were

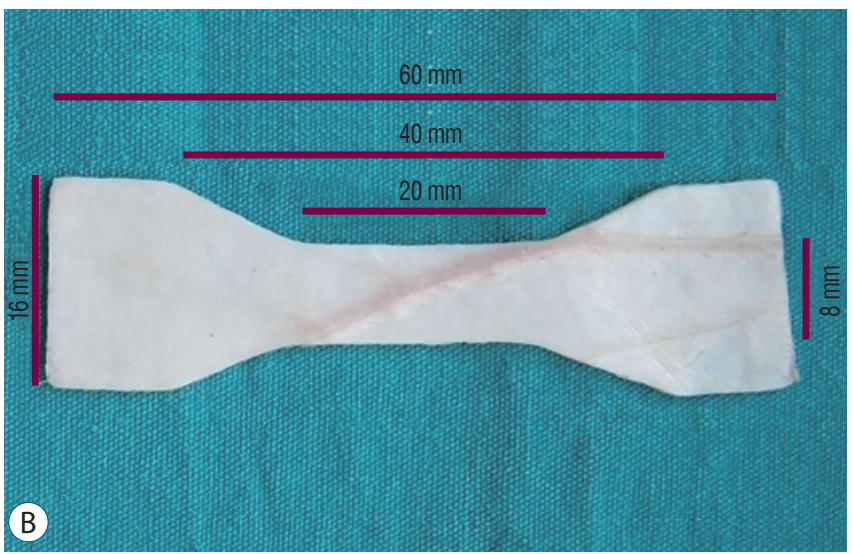

(A)

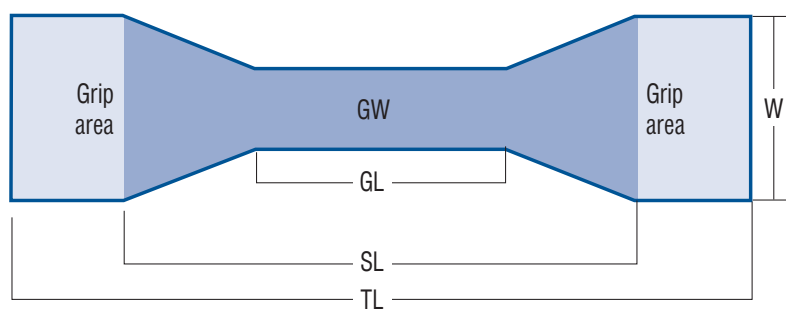

Duramater

Fig. 1. A : Dimensions of dura mater test specimens. B : Dimensions of the cranial dura mater specimens. *Thickness changes due to specimens. GW : gauge width, GL: gauge length, SL: shoulder length, TL: total length, W: total width, T: thickness*. 
made according to Japanese Industrial Standard (JISK6251-5; 2004).

The test specimens were gripped using custom made aluminium grips to allow better stress distribution over a wider gripping area. The bottom grip was rigidly attached within a bathing chamber to the base of the machine. The other grip was fixed to a load cell mounted to the vertical actuator. No further pre-load was applied to the specimens.

Fig. 1 also shows the dimensions and orientations of dura mater samples. The thickness of the samples was measured using a digital caliper micrometer gauge (model number SS17DV150, Zhejiang, China). A custom designed system was

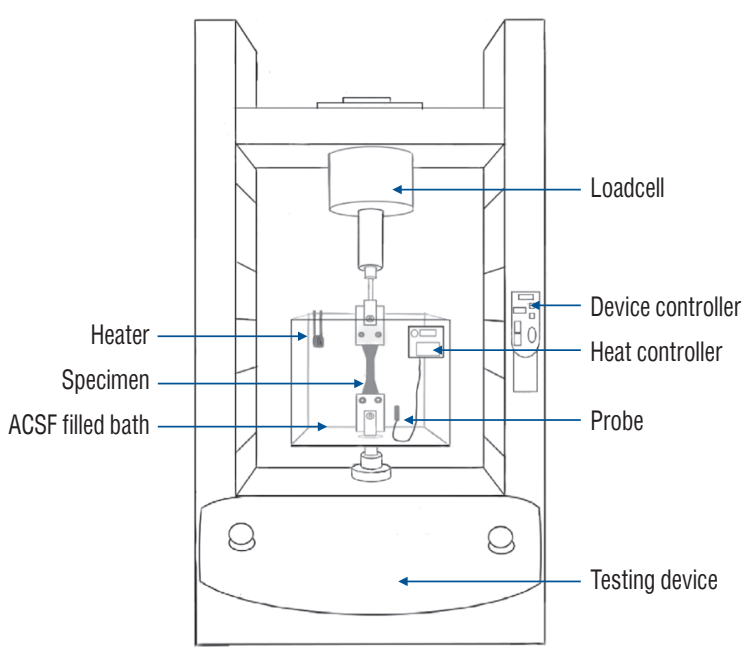

Fig. 2. Schematic representation of the test setup for human dura mater and dura mater substitutes biomechanics. ACSF : artificial cerebrospinal fluid. made to simulate in vivo conditions (Figs. 2 and 3). A custom designed cup was filled with artificial cerebrospinal fluid (sodium chloride $134 \mathrm{mM}$, potassium chloride $2.5 \mathrm{mM}$, magnesium chloride $1.3 \mathrm{mM}$, calcium chloride $2 \mathrm{mM}$, dipotassium hydrogen phosphate $1.25 \mathrm{mM}$, sodium hydrogen carbonate 26 $\mathrm{mM}$, and D-Glucose) and was heated to simulate human temperature.

\section{Mechanical analyses}

We used an axial compression machine (AG-IS 5 kN; Shimadzu Corporation, Kyoto, Japan). Uniaxial tension was described using JISK6251-5. The machine was equipped with a $500-\mathrm{N}$ load cell.

Tests were performed at a displacement rate of $10 \mathrm{~mm} / \mathrm{min}$ at $37.04 \pm 0.39^{\circ} \mathrm{C}$ in custom designed container filled with saline solution. The mean maximum tensile strength was recorded and analyzed by TRAPEZIUM X Materials Testing Software (version 1.1.2; AG-IS 5 kN, Shimadzu Corporation, Kyoto, Japan). Hooke's law is commonly expressed in terms of normalized parameters by calculating stress. The tensile stress calculation by Hooke's law is as follows :

Stress $(\mathrm{MPa})=\mathrm{P} / \mathrm{A}$

where $\mathrm{A}$ is the loaded cross-sectional area under tension and $\mathrm{P}$ is the loaded force in Newton's. Young's modulus, or elastic modulus, is the measure of the elastic deformation of the material under force. Young's modulus is equal to the longitudinal stress divided by the strain.
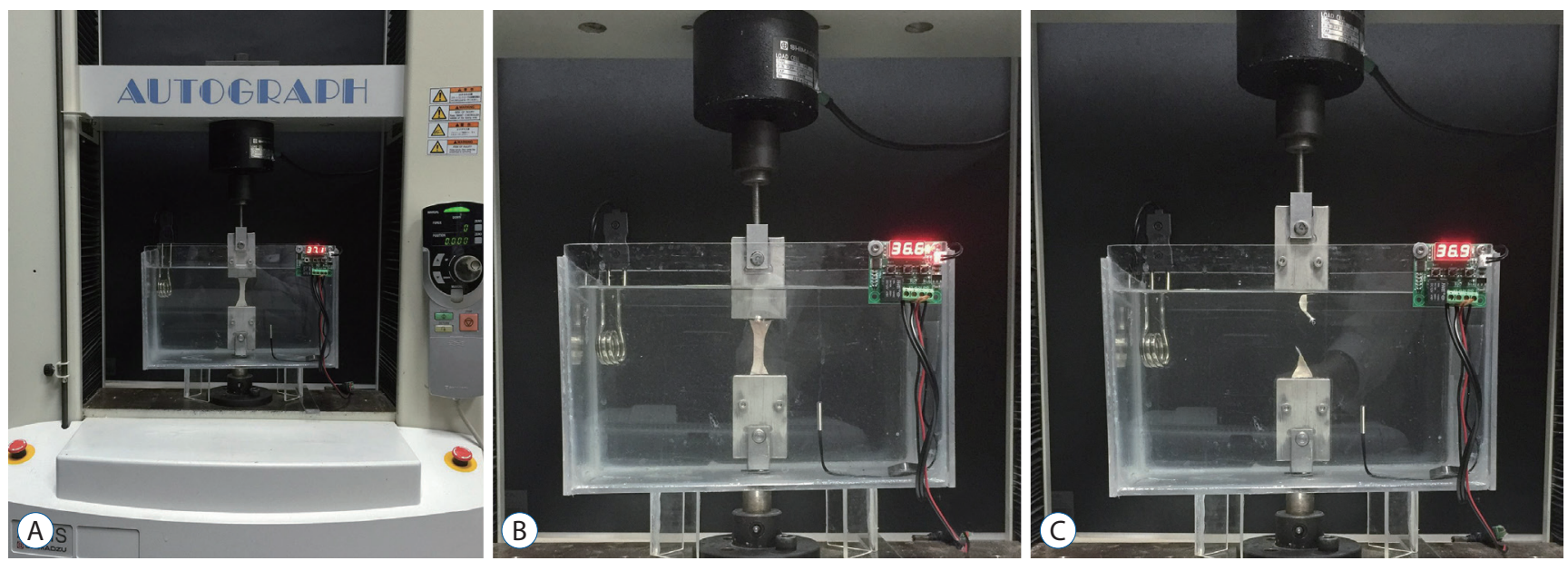

Fig. 3. The test setup ( $A$ ), and figures (B and $C$ ) showing the test specimen, the heating element, waterproof sensor, and digital thermometer controller, before and after the test. 


\section{Statistical analysis}

Tensile strength, thickness, Young's modulus and standard deviation values were calculated for the four groups. The mean tensile strengths of each group was statistically analysed with a Mann-Whitney U test (SPSS, ver. 15.0; SPSS, Chicago, IL, USA). Statistical results with $p<0.05$ were accepted as significant.

\section{RESULTS}

For the experimental results of tensile strength and thickness, the mean and standard deviation values for the test groups are shown in Table 1 . Stress and strain results for all groups are shown in Fig. 4. The mean maximum tensile strengths were $7.01 \pm 0.77 \mathrm{MPa}$ for group I, 22.03 $\pm 0.60 \mathrm{MPa}$ for

Table 1. Mean values of thickness, tensile strength and Young's modulus of specimens in all groups

\begin{tabular}{lcccccc}
\hline Group & Thickness $(\mathbf{m m})$ & $\begin{array}{c}p \text {-value } \\
\text { (thickness) }\end{array}$ & $\begin{array}{c}\text { Tensile strength } \\
(\mathrm{MPa})\end{array}$ & $\begin{array}{c}p \text {-value } \\
\text { (tensile strength) }\end{array}$ & $\begin{array}{c}\text { Young modulus } \\
(\mathrm{MPa})\end{array}$ & $\begin{array}{c}p \text {-value } \\
(\text { Young modulus) }\end{array}$ \\
\hline Group I $(\mathrm{n}=10)$ & $0.65 \pm 0.07$ & - & $7.01 \pm 0.77$ & - & $60.18 \pm 10.77^{\ddagger}$ & - \\
Group II $(\mathrm{n}=6)$ & $0.60 \pm 0.00$ & $0.107^{*}$ & $22.03 \pm 0.60$ & $0.004^{\dagger}$ & $18.26 \pm 8.45$ & $0.004^{\S}$ \\
Group III $(\mathrm{n}=6)$ & $0.50 \pm 0.00$ & $0.002^{*}$ & $19.59 \pm 0.65$ & $0.004^{\dagger}$ & $54.16 \pm 4.82$ & $0.423^{\S}$ \\
Group IV $(\mathrm{n}=6)$ & $0.40 \pm 0.00$ & $0.002^{*}$ & $3.51 \pm 0.63$ & $0.004^{\dagger}$ & $-^{\ddagger}$ & - \\
\hline
\end{tabular}

Values are presented as mean \pm standard deviation. Group I : cranial dura mater specimen; group II : Gore-Tex ${ }^{\circledR}$ Expanded Cardiovascular Patch Patch (W.L. Gore \& Associates Inc., Flagstaff, AZ, USA); group III : Durepair ${ }^{\circledast}$ (Medtronic Inc., Goleta, CA, USA); and group IV : Tutopatch ${ }^{\oplus}$ (Tutogen Medical GmbH, Neunkirchen am Brand, Germany). ${ }^{*}$-values of mean specimen thickness of group II, III, and IV compared with group I. ${ }^{\dagger} p$-values of mean maximum tensile strength of group II, III, and IV compared with group I. " Young's modulus of 1 specimen in group I and all specimens in group IV could not be calculated due to low tensile strength. ${ }^{\S} p$-values of mean Young modulus of group II and III compared with group I

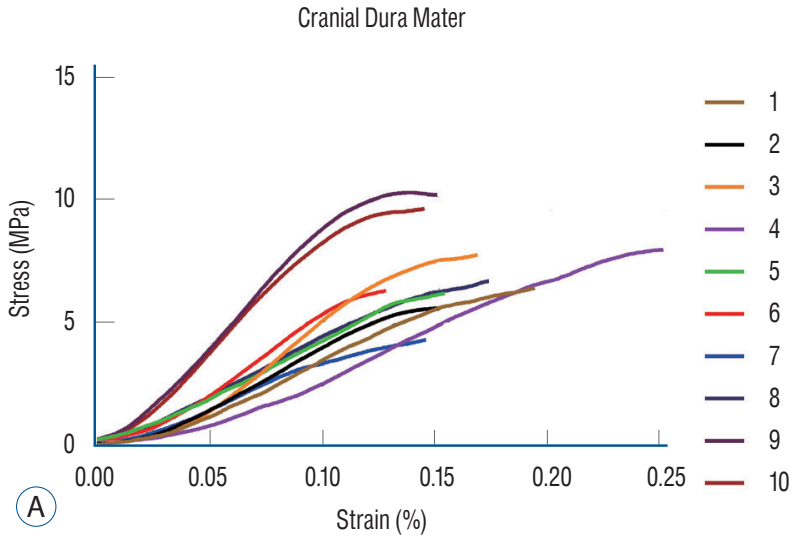

Durepair ${ }^{\circledR}$

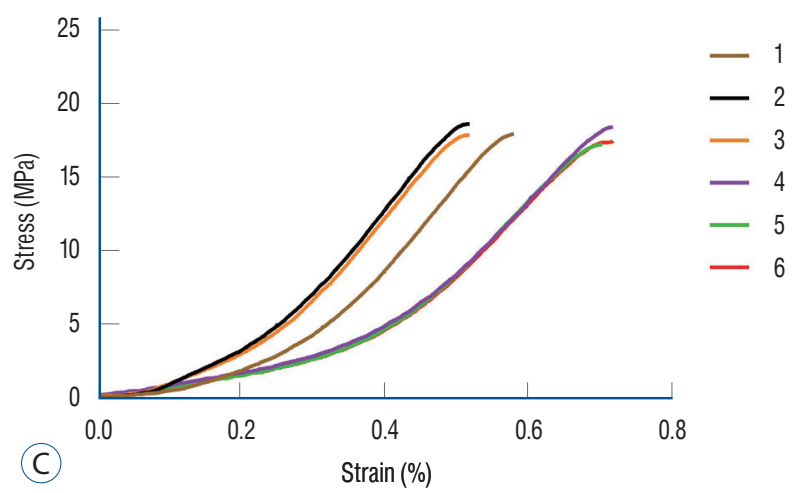

Gore-Tex ${ }^{\circledR}$

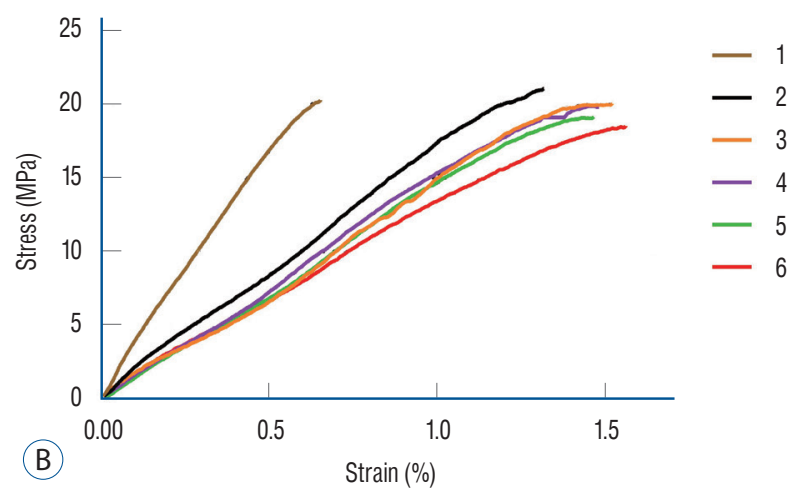

Tutoplast ${ }^{\circledR}$

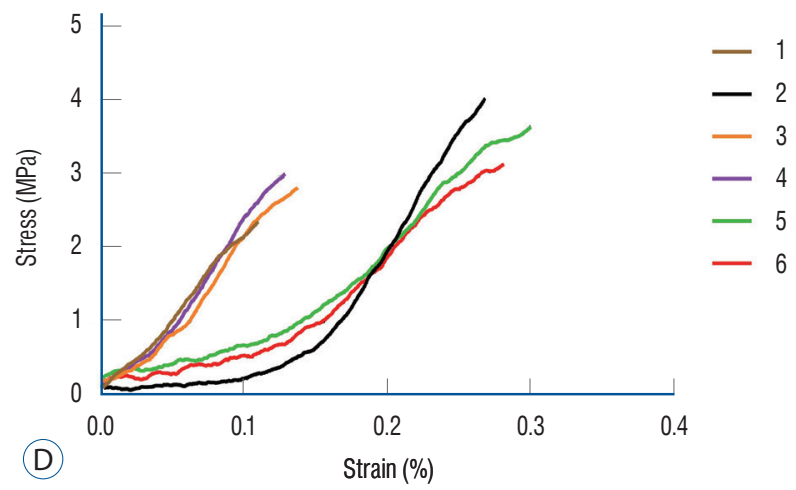

Fig. 4. A-D : Stress-strain curves for all groups with a displacement rate of $10 \mathrm{~mm} / \mathrm{min}$. 
group II 19.59 $\pm 0.65 \mathrm{MPa}$ for group III, and 3.51 $\pm 0.63 \mathrm{MPa}$ for group IV. The mean Young's modulus was $60.18 \pm 10.77 \mathrm{MPa}$ for group I, $18.26 \pm 8.45 \mathrm{MPa}$ for group II, and $54.16 \pm 4.82 \mathrm{MPa}$ for group III. The Young's modulus for group IV could not be calculated due to low tensile strength.

There was a statistically significant difference between the tensile strengths of all groups (group I/group II, $p=0.004$; group I/group III, $p=0.004$; group I/group IV, $p=0.004$; group II/group III, $p=0.004$; group II/group IV, $p=0.004$; and group III/group IV, $p=0.004$ ). The Gore-Tex ${ }^{\circledR}$ (W.L. Gore \& Associates Inc.) and Durepair ${ }^{\circledR}$ (Medtronic Inc.) materials were stronger than human dura mater. However, Tutopatch ${ }^{\circledR}(\mathrm{Tu}-$ togen Medical $\mathrm{GmbH}$ ) was weaker than human dura mater. There was statistically significant difference between the specimen thicknesses of all groups $(p<0.050)$ except for between group I and group II specimens $(p=0.107)$. There was no significant difference between the Young's modulus of group I and group III $(p=0.423)$.

\section{DISCUSSION}

Dura mater substitutes are widely used in neurosurgery to repair dural defects as a result of surgery, tumour invasion, congenital abnormalities and trauma. Neurosurgeons need to repair dura mater in 30\% of cranial operations ${ }^{23)}$. Surgeons prefer watertight or non-watertight dural reconstructions according to the etiology of the dural defects ${ }^{20)}$. Many dura mater substitutes and methods have been used over the past decades, such as synthetic materials, autologous tissues or human cadaveric dura mater ${ }^{4,7,11,12)}$. However, most of these substitutes were inconvenient because of postoperative complications. Nonautologous duraplasty has a complication rate of $10.61 \%{ }^{2)}$. Cadaveric dura mater graft use is a risk factor for piron (Creutzfelt-Jakob disease) transmission ${ }^{9)}$. Dura mater substitudes associated with pseudomeningocele, aseptic meningitis, and persistent cerebrospinal leakage ${ }^{15)}$.

All surgeons want to use an ideal dura mater substitute for dural defects. The biomechanical properties of dura mater substitutes should be resistant and should shape the material. In our study, we compared the biomechanical properties of cranial human dura mater and three dura mater substitutes.

Protasoni et al. ${ }^{17)}$ described three different layers of dura mater. The outer layer, which is the thinnest, consists of fibro- blasts, collagen and elastic fibres. The median layer consists of vascularized fibrous dura. The innermost layer, which is known as the cell layer, is firmly attached to the arachnoid layer. Tensile strength depends on collagen fibril orientations $^{17)}$. Lee and Alexander stated that the amount of collagen was related to the amount of scar tissue $\mathrm{e}^{13,21)}$.

Filippi et al." stated that they had good outcomes with the use of Tutopatch ${ }^{\circledR}$ (Tutogen Medical GmbH) in 32 cases. They also showed that Tutopatch ${ }^{\circledR}$ (Tutogen Medical $\mathrm{GmbH}$ ) was resistant, easy to use, less expensive than collagen substitutes. Wilcox et al. ${ }^{24)}$ demonstrated that bovine spinal dura mater had high viscoelastic properties in both longitudinal and circumferential directions. Patin et al. ${ }^{16)}$ found that the longitudinal tensile strength of human lumbar dura mater was greater than its transverse tensile strength as human lumbar dura mater had a longitudinal structure. In our study, we used only uniaxial tension because cranial dura mater has isotropic mechanical properties.

Patin et al. ${ }^{16)}$ also stated that the mean peak tensile forces of human lumbar dura mater were $80 \mathrm{~N}$ for the longitudinal direction and $15 \mathrm{~N}$ for the transverse direction. In our study, the mean peak tensile force was $24.41 \pm 3.32 \mathrm{~N}$ for cranial human dura mater, $95.98 \pm 3.83 \mathrm{~N}$ for Gore-Tex ${ }^{\circledR}$ (W.L. Gore \& Associates Inc.), $72.78 \pm 1.91 \mathrm{~N}$ for Durepair ${ }^{\circledR}$ (Medtronic Inc.), and was $8.28 \pm 2.47 \mathrm{~N}$ for Tutopatch ${ }^{\circledR}$ (Tutogen Medical GmbH).

Runza et al. ${ }^{18)}$ used dumbbell-shaped specimens to measure the tensile strengths of human lumbar dura mater and bovine dura mater. Runza et al. ${ }^{18)}$ found that longitudinal samples had more tensile strength than circumferential samples.

Zerris et al. ${ }^{28)}$ stated that the mean tensile strength of Durepair ${ }^{\circledR}$ (Medtronic Inc.) was $22.70 \pm 2.83 \mathrm{MPa}$ and the mean thickness was $0.50 \pm 0.02 \mathrm{~mm}$ (Table 2). In our study, we found a mean tensile strength of $19.80 \pm 0.80 \mathrm{MPa}$ and a mean thickness of $0.50 \pm 0.00 \mathrm{~mm}$ for Durepair ${ }^{\circledR}$ (Medtronic Inc.) samples.

van Noort et al. ${ }^{22)}$ stated that the mean tensile strength of human cranial dura mater was 4,70 MPa. Sacks et al. ${ }^{19)}$ stated that the mean tensile strength of human cranial dura mater was $12.76 \pm 1.65 \mathrm{MPa}$. Wolfinbarger et al. ${ }^{25)}$ stated that the mean tensile strength of human cranial dura mater was 6.65土 $0.14 \mathrm{MPa}$. McGarvey et al. ${ }^{14)}$ stated that the mean tensile strength of human cranial dura mater was $9.41 \pm 1.54 \mathrm{MPa}$. In our study, we found a mean tensile strength of 6.37 $\pm 1.94 \mathrm{MPa}$.

Yamada et al. ${ }^{26)}$ used a rectangular test sample $(40 \times 5 \mathrm{~mm})$ 
of human dura mater and found a mean tensile strength of $8.80 \pm 2.37 \mathrm{MPa}$ and a mean thickness of $6.26 \pm 2.37 \mathrm{~mm}$.

Famaey et al. ${ }^{6}$ compared stretchable and non-stretchable expanded PTFE by axial tension and found a strength of 41.48 $\pm 3.34 \mathrm{MPa}$ for stretchable expanded PTFE and 32.40土3.80 MPa for non-stretchable expanded PTFE. However, they used a rectangular test sample $(10 \times 5 \mathrm{~mm})$ for the axial tension test. We used a standard dumbbell-shaped specimen for measuring tensile strength and found strength of 22.85 $\pm 0.91 \mathrm{MPa}$ for PTFE.

The Young's modulus represents the amount of tension that must be applied to the material to create elastic strain. A material with a high Young's modulus indicates that it is difficult to stretch elastically, whereas a low value indicates that it can flex elastically. Although group II had high tensile stress compared to the other groups, the mean Young's modulus of group II was lower than that of group I and III. This finding means that Gore-Tex ${ }^{\circledR}$ (W.L. Gore \& Associates Inc.) material is more elastic under tensile stress than the other materials. The mean Young's modulus of group IV could not be calculated due to the low tensile stress of the material.

van Noort et al. ${ }^{22)}$ stated that the Young's modulus of human dura mater was 21.3-48.0 MPa, whereas McGarvey et al. ${ }^{14)}$ stated that the Young's modulus of human dura mater

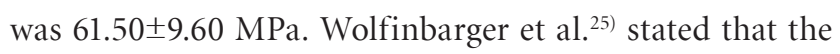
Young's modulus of human dura mater was $69.50 \pm 1.28 \mathrm{MPa}$. In our study, the mean Young's modulus of group I was $60.18 \pm$ 10.77 $\mathrm{MPa}$, which was similar to the results of Zerris et al. ${ }^{28)}$ found a Young's modulus of $69.94 \pm 9.49$ for Durepair ${ }^{\circledR}$ (Medtronic Inc.). In our study, the mean Young's modulus of group III was $54.16 \pm 4.82 \mathrm{MPa}$.
Cantore et al. ${ }^{3)}$ used cadaveric dura in 804 patients. Before using the cadaveric dura, they stored the samples in 70\% ethyl alcohol and sterilized them with gamma rays. However, the authors did not report mechanical tests, and the study used cadaveric dura from donors with spreading Creutzfeldt-Jakob disease ${ }^{3)}$. Yamada et al. ${ }^{27)}$ developed bio absorbable artificial dura mater composed of polymers that had mean tensile strength of $11.40 \pm 2.84 \mathrm{MPa}$ with the usage of a rectangular test sample. Many dural substitutes have been manufactured, but autologous pericranium is the best choice because it is non-immunogenic, inexpensive, and has reduced cerebrospinal fluid leaks and infection compared to substitutes ${ }^{5)}$. Although autologous pericranium is the best choice, there are some disadvantages such as surgeons need additional incisions and time, difficulty in establishing a watertight closure, and insufficient graft material for covering large dural defects.

The limitations of this study were that we used dura samples that were frozen and then thawed. How the freeze-thaw cycle affected dural biomechanics was not investigated. Biomechanical properties should be tested after the healing process in vivo.

The strength properties of the material used in neurosurgery are clinically important. The biomechanical properties of the material should be close to the thickness, impact absorbency and elasticity of the tissue to be used. The properties of commercially available biomaterials may vary. The choice of biomechanical material closest to duramater elasticity and thickness for duramater tissue will provide a positive effect to reduce suture stress in tissue and surgery. Because the human dura mater is perfect impact absorber and barrier. Biomechanical property is one of the property of ideal dura mater

Table 2. Mechanical properties of human dura mater and dural substitudes in the literature

\begin{tabular}{|c|c|c|c|c|}
\hline Study & Specimen & Thickness (mm) & Tensile strength (MPa) & Young modulus (MPa) \\
\hline Zerris et al. ${ }^{28)}$ & Durepair ${ }^{\oplus *}$ & $0.50 \pm 0.02$ & $22.70 \pm 2.83$ & $69.94 \pm 9.49$ \\
\hline van Noort et al. ${ }^{22)}$ & Cranial dura mater & - & 4.70 & $21.3-48.0$ \\
\hline Sacks et al. ${ }^{19)}$ & Cranial dura mater & - & $12.76 \pm 1.65$ & - \\
\hline Wolfinbarger et al. ${ }^{25)}$ & Cranial dura mater & - & $6.65 \pm 0.14$ & $69.50 \pm 1.28$ \\
\hline McGarvey et al. ${ }^{14)}$ & Cranial dura mater & - & $9.41 \pm 1.54$ & $61.50 \pm 9.60$ \\
\hline Yamada et al. ${ }^{26)}$ & Cranial dura mater & $6.26 \pm 2.37$ & $8.80 \pm 2.37$ & - \\
\hline Famaey et al. ${ }^{6}$ & Non-stretchable expanded PTFE & - & $41.48 \pm 3.34$ & - \\
\hline Famaey et al. ${ }^{6}$ & Stretchable expanded PTFE & - & $32.40 \pm 3.80$ & - \\
\hline
\end{tabular}

Values are presented as mean \pm standard deviation or number. *Medtronic Inc., Goleta, CA, USA. PTFE : polytetrafluoroethylene 
substitutes. Many biocompatible tissues and biomaterials are used to repair dura mater defects.

\section{CONCLUSION}

The biomechanical properties of three dura mater substitutes were investigated and compared with those of human dura mater. All dural substitutes had different biomechanical properties, but they were used safely and effectively to heal dura mater defects. In the future, care should be taken to ensure that the biomechanical properties of dural substitutes are similar to those of human dura mater, and this knowledge may be used for determining the material properties of tissue engineering scaffolds. Clinical evaluation may also be required in order to clearly determine the surgical complications related to each dura mater substitute.

\section{CONFLICTS OF INTEREST}

No potential conflict of interest relevant to this article was reported.

\section{INFORMED CONSENT}

This type of study does not require informed consent.

\section{AUTHOR CONTRIBUTIONS}

\author{
Conceptualization : CK, HEA, HH \\ Data curation : CK, HEA, IK \\ Formal analysis : $\mathrm{CK}, \mathrm{BH}, \mathrm{MA}$ \\ Funding acquisition : $\mathrm{CK}$ \\ Methodology : CK, BH, OK \\ Project administration : CK, GS, HH \\ Visualization : $\mathrm{HH}, \mathrm{MA}$ \\ Writing - original draft : CK, HEA, IK, OK \\ Writing - review \& editing: CK, HEA, IK, OK, HH
}

\section{- Acknowledgements}

The authors acknowledge the staff of the Dokuz Eylul University School of Medicine Health Science Institute Biomechanics Laboratory and Izmir Forensic Medicine Institution for their technical support in the completion of this study.

\section{References}

1. Aliredjo RP, de Vries J, Menovsky T, Grotenhuis JA, Merx J : The use of Gore-Tex membrane for adhesion prevention in tethered spinal cord surgery: technical case reports. Neurosurgery 44 : 674-677, 1999

2. Azzam D, Romiyo P, Nguyen T, Sheppard JP, Alkhalid Y, Lagman C, et al. : Dural repair in cranial surgery is associated with moderate rates of complications with both autologous and nonautologous dural substitutes. World Neurosurg 113 : 244-248, 2018

3. Cantore G, Guidetti B, Delfini R : Neurosurgical use of human dura mater sterilized by gamma rays and stored in alcohol: long-term results. J Neurosurg 66 : 93-95, 1987

4. Chaplin JM, Costantino PD, Wolpoe ME, Bederson JB, Griffey ES, Zhang $W X$ : Use of an acellular dermal allograft for dural replacement: an experimental study. Neurosurgery 45 : 320-327, 1999

5. Danish SF, Samdani A, Hanna A, Storm P, Sutton L : Experience with acellular human dura and bovine collagen matrix for duraplasty after posterior fossa decompression for Chiari malformations. J Neurosurg 104 : 16-20, 2006

6. Famaey N, Verhoeven J, Jacobs S, Pettinari M, Meyns B : In situ evolution of the mechanical properties of stretchable and non-stretchable ePTFE vascular grafts and adjacent native vessels. Int J Artif Organs $37: 900-910,2014$

7. Filippi R, Schwarz M, Voth $D$, Reisch R, Grunert P, Perneczky A : Bovine pericardium for duraplasty: clinical results in 32 patients. Neurosurg Rev 24 : 103-107, 2001

8. FungYC : Biomechanics: mechanical properties of living tissues, ed 2. New York : Springer-Verlag, 1981

9. Hoshi K, Yoshino H, Urata J, Nakamura Y, Yanagawa H, Sato T : Creutzfeldt-Jakob disease associated with cadaveric dura mater grafts in Japan. Neurology 55 : 718-721, 2000

10. Inoue HK, Kobayashi S, Ohbayashi K, Kohga H, Nakamura M : Treatment and prevention of tethered and retethered spinal cord using a Gore-Tex surgical membrane. J Neurosurg 80 : 689-693, 1994

11. Knopp U, Christmann F, Reusche E, Sepehrnia A : A new collagen biomatrix of equine origin versus a cadaveric dura graft for the repair of dural defects--a comparative animal experimental study. Acta Neurochir (Wien) $147:$ 877-887, 2005

12. Laun A, Tonn JC, Jerusalem C : Comparative study of lyophilized human dura mater and lyophilized bovine pericardium as dural substitutes in neurosurgery. Acta Neurochir (Wien) $107:$ 16-21, 1990 
13. Lee $\mathrm{CK}$, Alexander $\mathrm{H}$ : Prevention of postlaminectomy scar formation. Spine (Phila Pa 1976) 9 : 305-312, 1984

14. McGarvey KA, Lee JM, Boughner DR : Mechanical suitability of glycerolpreserved human dura mater for construction of prosthetic cardiac valves. Biomaterials 5 : 109-117, 1984

15. Moskowitz SI, Liu J, Krishnaney AA : Postoperative complications associated with dural substitutes in suboccipital craniotomies. Neurosurgery $64: 28-33,2009$

16. Patin DJ, Eckstein EC, Harum K, Pallares VS : Anatomic and biomechanical properties of human lumbar dura mater. Anesth Analg 76 : 535540, 1993

17. Protasoni M, Sangiorgi S, Cividini A, Culuvaris GT, Tomei G, Dell'Orbo C, et al. : The collagenic architecture of human dura mater. J Neurosurg 114 : 1723-1730, 2011

18. Runza M, Pietrabissa R, Mantero S, Albani A, Quaglini V, Contro R : Lumbar dura mater biomechanics: experimental characterization and scanning electron microscopy observations. Anesth Analg 88 : 13171321, 1999

19. Sacks MS, Jimenez Hamann MC, Otaño-Lata SE, Malinin TI : Local mechanical anisotropy in human cranial dura mater allografts. J Biomech Eng $120: 541-544,1998$

20. Sade B, Oya $\mathrm{S}$, Lee JH : Non-watertight dural reconstruction in meningioma surgery: results in 439 consecutive patients and a review of the literature. Clinical article. J Neurosurg 114 : 714-718, 2011
21. Topsakal C, Akpolat N, Erol FS, Ozveren MF, Akdemir I, Kaplan M, et al. : Seprafilm superior to Gore-Tex in the prevention of peridural fibrosis. J Neurosurg $101:$ 295-302, 2004

22. van Noort R, Black MM, Martin TR, Meanley S : A study of the uniaxial mechanical properties of human dura mater preserved in glycerol. Biomaterials 2 : 41-45, 1981

23. Warren WL, Medary MB, Dureza CD, Bellotte JB, Flannagan PP, Oh MY, et al. : Dural repair using acellular human dermis: experience with 200 cases: technique assessment. Neurosurgery 46 : 1391-1396, 2000

24. Wilcox RK, Bilston LE, Barton DC, Hall RM : Mathematical model for the viscoelastic properties of dura mater. J Orthop Sci 8 : 432-434, 2003

25. Wolfinbarger L, Zhang YX, Adam BLT, Homsi D, Gates K, Sutherland V: Biomechanical aspects on rehydrated freeze-dried human allograft dura mater tissues. J Appl Biomater 5 : 265-270, 1994

26. Yamada K, Miyamoto S, Nagata I, Kikuchi H, Ikada Y, Iwata H, et al. : Development of a dural substitute from synthetic bioabsorbable polymers. J Neurosurg 86 : 1012-1017, 1997

27. Yamada K, Miyamoto S, Takayama M, Nagata I, Hashimoto N, Ikada Y, et al. : Clinical application of a new bioabsorbable artificial dura mater. J Neurosurg 96 : 731-735, 2002

28. Zerris VA, James KS, Roberts JB, Bell E, Heilman CB : Repair of the dura mater with processed collagen devices. J Biomed Mater Res B Appl Biomater 83 : 580-588, 2007 